\title{
Can Philanthropy Enable Collective Action to Conserve Rivers? Insights from a Decade of Collaboration in the Colorado River Basin
}

\author{
Gina G. Gilson, ${ }^{a, \# ; ~ D u s t i n ~ E . ~ G a r r i c k ~}{ }^{a, b}$ \\ aSchool of Geography and the Environment, University of Oxford, Oxford, UK \\ ${ }^{\mathrm{b}} \mathrm{School}$ of Environment, Resources and Sustainability, University of Waterloo, Ontario, Canada
}

\#Corresponding author. e-mail: gina.gilson@gtc.ox.ac.uk

\begin{abstract}
Philanthropy plays an important but often invisible role in conserving rivers. We examine the influence of philanthropy on collective action and collaborative governance within the Colorado River Basin, a region where philanthropic support has been growing to achieve conservation objectives. Our short communication combines financial data, interviews, and documentary evidence to capture the opportunities and risks associated with philanthropy's increasing role. Financial expenditures are substantial, averaging \$30.8 million USD per year from six large foundations (2013-2019). This funding has enabled collective action, particularly at the basin level, by strengthening or creating new forums for collaboration and investing in technical expertise to equip a broader range of voices in decision-making. It has also favoured market-based strategies and discourses, created dependencies for smaller organisations, and, in some instances, reinforced structural barriers to participation. We recommend transparent reporting of philanthropic spending related to collective action and conservation governance, and argue that foundations should explicitly consider and address legacies of exclusion for marginalised actors and groups.
\end{abstract}

Keywords: collective action, conservation finance, freshwater conservation, governance, market-based conservation, philanthropy

\section{INTRODUCTION}

Philanthropy has a growing profile in conservation governance with multiple channels of influence that affect conservation priorities, public discourse, and policy choices (Farley 2018; Holmes 2012). However, the increasing role of non-governmental entities, such as philanthropic foundations, is often overlooked in research on natural resource governance (Burow et al. 2019). Our short communication examines the role of philanthropy in the Colorado River Basin (CRB), where a series of basin-level planning efforts have been

\begin{tabular}{|c|c|}
\hline \multicolumn{2}{|c|}{ Access this article online } \\
\hline Quick Response Code: & \multirow{2}{*}{$\begin{array}{l}\text { Website: } \\
\text { www.conservationandsociety.org.in }\end{array}$} \\
\hline & \\
\hline 든 & $\begin{array}{l}\text { DOI: } \\
\text { 10.4103/cs.cs_225_20 }\end{array}$ \\
\hline
\end{tabular}

shaped by philanthropic giving over the past decade. We focus specifically on philanthropy's role in large-scale collective action to achieve conservation goals that require basin-wide coordination.

TheCRBhas been describedas "themost legislated, mostdebated, and most litigated river in the entire world" (Reisner 1993: 120). The basin is governed by a relatively decentralised and fragmented system, with a number of different authorities and institutions informing its management (Gerlak et al. 2013). Amidst sustained drought, climate change, and structural imbalances between supply and demand, "conflict has given way to collaboration as the strategy of choice in addressing water issues" (Karambelkar and Gerlak 2020: 1). In this period of unprecedented collaboration (Gerlak et al. 2013; Fleck 2016), the CRB has become a test bed for experiments in collaborative governance and benefit sharing (Koebele 2020). These trends respond to system-wide, large-scale collective action challenges associated with upstream-downstream and inter-sectoral competition that require cooperation and conflict resolution at the basin level (Garrick 2015).

Copyright: Gilson and Garrick (C 2021. This is an open access article distributed under the terms of the Creative Commons Attribution License, which permits unrestricted use and distribution of the article, provided the original work is cited. Published by Wolters Kluwer - Medknow, Mumbai | Managed and supported by the Ashoka Trust for Research in Ecology and the Environment (ATREE), Bangalore. For reprints contact: WKHLRPMedknow_reprints@wolterskluwer.com 
Environmental recovery plans have followed basin-wide trends, shifting from zero-sum litigation strategies towards experimentation with markets, incentives, and benefit sharing. In 2005, a major report titled Conservation Priorities for the Colorado River Delta - supported by a consortium including seven foundations - recommended a binational agreement to secure "quantified, dedicated sources of water for the environment through treaty agreement, national policy, or market-based mechanisms" (Zamora-Arroyo et al. 2005: 68). Shortly after, conservation groups promoted market-based mechanisms in the 2006 "Conservation Before Shortage" proposal, submitted by a group of non-profit organisations as input for designing new shortage management criteria (Gillon et al. 2006). These trends have led to a current era where markets and incentives go hand-in-hand with governance, especially in collaborative decision-making processes.

As strategies shifted, philanthropic groups became increasingly involved in management in the CRB. A new phase of philanthropy was marked in 2016 by the launch of the Water Funder Initiative (WFI), a collaborative effort formed by eight foundations to identify water solutions through strategic philanthropic investments (WFI 2016). In recognising the problems posed by fragmented management, the WFI lists "improve water governance" as a priority strategy on their website (waterfunder.org), stating that "philanthropy can promote governance structures that raise up leaders representative of, and accountable to, the communities they serve, including disadvantaged communities."

Today, looming water shortages are driving efforts to renegotiate water sharing rules and create new spaces of collaboration, as the basin's two largest reservoirs are projected to dip below 30\% full by 2023 (Fleck and Udall 2021). Through strategic investments, philanthropic organisations-not just their grantees - have earned a seat at the table, seen in examples like the Walton Family Foundation's (WFF) steering

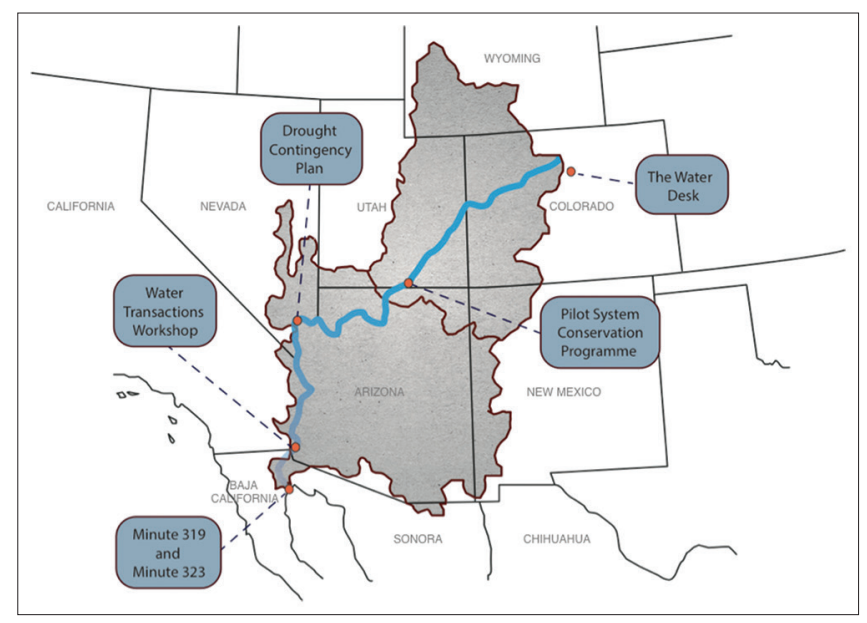

Figure 1

Map of the Colorado River Basin with examples of projects supported by philanthropy. The WFI played a role in the Minute 323 agreement and the Lower Basin Drought Contingency Plan. The WFF supported the Pilot System Conservation Programme, the River Network's Water Transactions Workshop, and the launch of the Water Desk committee role for the Lower Basin Drought Contingency Plan (Central Arizona Project 2016). These philanthropic groups are focusing not just on collaboration within a single authority or coalition, but at the basin level (WFI 2020) (Figure 1). Our case study explores the influence of philanthropic funding in the $\mathrm{CRB}$, and its role in fostering collective action and collaborative governance amongst conservation actors.

\section{METHODS}

To understand the influence of philanthropy on large-scale collective action, we collected data on philanthropic expenditures and interviewed stakeholders affected by these funds. We supplemented these with relevant documentary evidence regarding the role of philanthropy in basin governance since 2009, including media, websites, and planning documents. The data collection was iterative, involving a sequence of unstructured interviews with key informants, an initial audit of grant databases, a further round of semi-structured interviews, and coding and classification of both the financial data and the interview responses. Though philanthropy can include a range of charitable voluntary actions for the public good, we focus on philanthropic foundations, which redistribute the benefits from enterprise for the greater benefit of humanity (Holmes 2012).

We employed purposive sampling techniques to identify interview participants, and conducted 18 interviews representing 5 stakeholder groups between June and August of 2018. Each interview was conducted according to a guide with three main themes: 1) philanthropic funders: trends and their importance to organisations; 2) changes supported by philanthropic investment: policy, projects, organisations and their networks; and 3) opportunities and challenges: working with philanthropic funders. Interviews were recorded, transcribed, and coded in NVivo according to collective action theory, which has evolved from research aiming to understand the factors that influence cooperation and self-organization for sustainable natural resource governance (Ostrom 2009). Codes included: 1) forms of collective action: development of institutions; resource mobilisation; coordination activities and information sharing, and 2) factors facilitating collective action: characteristics of the collective problem; characteristics of the group; institutional arrangements; and the actions of national governments and external actors (Poteete and Ostrom 2004). Prior to the interview, a consent form was reviewed and signed by each participant confirming that they understood the purpose of the research and that anonymity would be maintained. The study was approved by the Central University Research Ethics Committee (CUREC) of the University of Oxford (reference: SOGE 18A-80).

Financial analysis was undertaken for all funders that were identified in more than one interview $(n=8)$. Only six foundations were included in the results, as one had a non-functional database, and one did not have public-facing documents. Databases, websites, and annual reports were searched, and only grants attributable to water-related 
conservation activities in the CRB were included. For the WFF, the amount of funding explicitly dedicated to the CRB was listed in five of the last seven years (2013 to 2019; all but 2015 and 2019). For 2019, detailed grant descriptions were used to provide an estimate of CRB-specific funding. In 2015, the amount of CRB-specific funding was estimated based on the fraction of total environment spending dedicated to the CRB in all other years. Because of WFF's prevalence, a subset of grantee organisations of various sizes was selected for additional analysis of IRS 990 documents and annual reports to provide insights about how foundation philanthropy relates to organisational finances. All amounts were updated to their equivalent in 2020 USD.

\section{RESULTS: SUBSTANTIAL FLOWS INTO THE BASIN}

Our results can be summarised by four key findings. First, there is a substantial amount of philanthropic funding flowing into the CRB. Second, philanthropy is enabling forms of basin-level collective action by strengthening coordination mechanisms (e.g., planning processes, joint modelling) and creating new avenues of collaboration and information sharing. Third, philanthropy is providing funds to facilitate collective action by building the capacity of key actors to engage in basin-level processes. Finally, participants noted a lack of diversity in the funding community and potential pitfalls for grantees related to exclusion.

The six funders analysed contributed an average of approximately \$30.8 million USD per year between 2013-2019, with a low of $\$ 20.6$ million in 2015 and a high of $\$ 42$ million in 2017. This is likely an under-estimation, as grant databases provided limited information about the grant purposes, and only grants attributable explicitly to water-related work in the CRB were included. Four of the analysed foundations are associated with the WFI (WFF, Bechtel Foundation, Hewlett Foundation, and Pisces Foundation). The WFF was the most frequently identified funder, with an average annual expenditure ranging from \$17 million in 2013 to \$23.4 million in 2019 (Figure 2). Philanthropic funding pales in comparison with government budgets, such as the Federal Bureau of Reclamation, which spent $\$ 252$ million on CRB operations in 2017. However, foundations are able to leverage their investments at the basin scale by shaping policy agendas and conservation priorities, developing new funding sources, strengthening water governance, and improving communication to build political will (WFI 2016).

Second, philanthropy is enabling forms of collective action at the basin level by strengthening coordination mechanisms and creating new ones. All but one interview participant referenced the role of philanthropy in supporting collaboration and information sharing. For example, the WFI supported progress on Minute 323, an international agreement that updates how the United States and Mexico share water in the CRB (WFI 2020). This agreement advances binational restoration activities, and builds on prior commitments under Minute 319, which

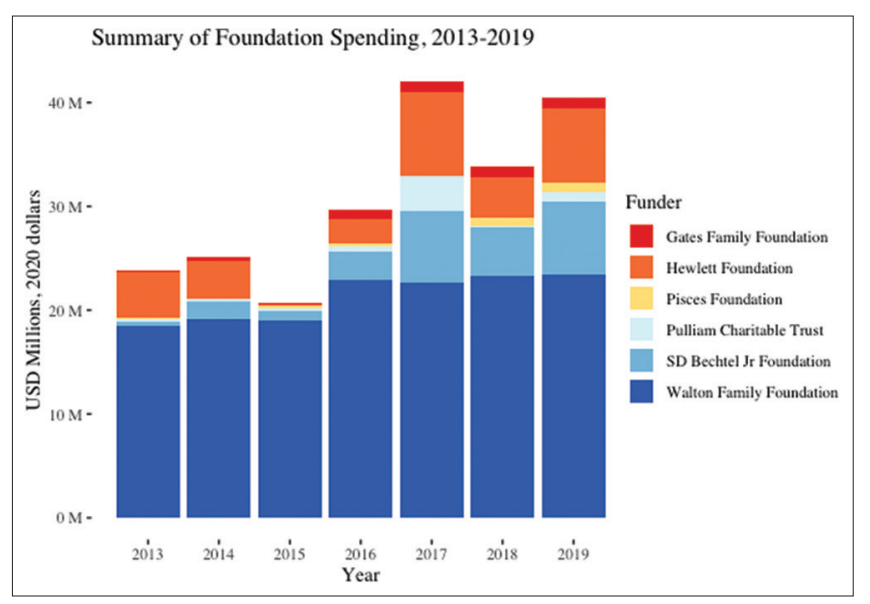

Figure 2

Philanthropic funds from six identified funders have increased in the $C R B$. In the analysed period, the WFF's reported spending in the basin is double that of the other foundations combined

enabled a historic flood pulse in the Colorado River Delta (Pitt and Kendy 2017). New avenues of collaboration include efforts such as the Pilot System Conservation Programme, which explored the feasibility of demand management programmes (Tory 2017), or stakeholder events such as the River Network's Water Transactions Workshop-both supported by the WFF (NU1C3, River Network 2017). As one participant remarked, "[Philanthropy] has been bringing in more people to talk to and think through ideas with, and to scale up our good ideas" (NUW2).

Third, philanthropy is facilitating basin-level collective action by building the capacity of conservation actors to engage in policy and planning processes. This support includes funding to improve technical expertise for the institutional work that is required for policy efforts, and for capacity on the ground to overcome conflicts and third-party impacts of conservation strategies. For example, while market-based strategies have increased environmental water acquisitions in the CRB (Kendy et al. 2018), their scalability has hinged on parallel and coordinated investments in policy and planning. One participant stated that funders support transactions, but also fund lobbying and advocacy to improve the chances of markets developing (NUW2). Funds have been used to respond to concerns from agricultural water users and cushion the risks of conservation strategies, such as protecting farmers experimenting with less water-intensive crops or safeguarding water users from forfeiting their water rights due to non-use.

Finally, though many grantees emphasised collaborative relationships with their funders, some voiced concerns of pitfalls related to exclusion and a lack of diversity in the funding community. As explained by NLXA2, "the influence from a foundation can promote collaboration and more efficiency, but at the same, it creates some obstacles [for those who do not receive funding]." Seven participants discussed the risk of frustration and conflict when non-grantees are excluded from collaborative discussions. Eleven participants recognised that philanthropy influences 
who is given a 'seat at the table,' with some noting concern that dominant funders are drowning out other voices (ULXN). Those who do receive foundation funding may also suffer from a lack of independence, as our extended financial analysis of grantees revealed that some recipients may rely heavily on a single funder. While the analysed subset of recipient organizations received a median of $7.26 \%$ of their annual non-governmental grants from the WFF, this ranged from $0.5 \%$ to $92 \%$ (Figure 3 ).

\section{DISCUSSION}

Philanthropic giving in the Colorado River suggests two opportunities to harness the benefits of philanthropy while mitigating its risks. First, our analysis illustrates that reliable, comparable, and publicly available information on philanthropic expenditures, priorities, and behaviours is surprisingly scarce, echoing the OECD's (2018) analysis of private philanthropy for sustainable development. In the CRB, there has been growing scrutiny of philanthropic actors and their influence, seen in recent journalism that criticises the role of the WFF in setting policy agendas and questions their influence on research groups, non-profits, and journalism (Marston 2021). Transparency about the nature, scale and trajectory of funding can help to address concerns. The OECD (2018) identified two strategies to improve transparency, which can lead to benefits such as more effective coordination, new partnerships, and increased legitimacy: first, leveraging existing platforms to produce comparable data, and second, ensuring accessibility by making such data a public good. Further, we suggest that philanthropists should report on their own activities, including their participation in wider processes and roles played (e.g., amount spent for work on the Drought Contingency Plan, and how funders were involved in the process). The WFI could be an ideal forum to engage basin stakeholders in co-producing a standardised reporting framework that makes these suggestions concrete. Efforts to improve reporting of philanthropic expenditures and their influence on governance processes and outcomes is analogous to recent calls for subsidy accountability in the public sector (Dempsey et al. 2020).

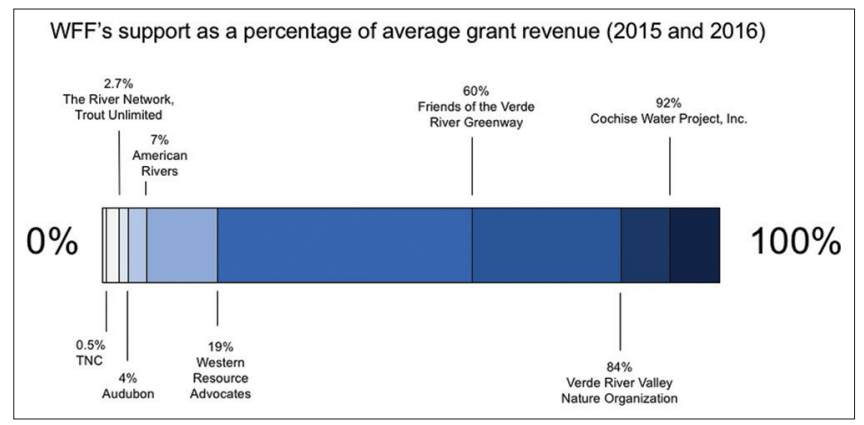

Figure 3

For the years of 2015 and 2016, grant amounts from WFF were compared to total non-governmental grants received, as reported in IRS-990 tax

documents. While large organisations have diverse funding streams, small organisations rely disproportionately on individual funders
Second, efforts to foster collective action at the basin-level can combat systemic barriers to participation and representation in decision-making. In the CRB, Tribal Nations were insufficiently consulted in the process of developing the Interim Guidelines for the Lower Basin (Bureau of Reclamation 2020), and were later incorporated into the Drought Contingency Plan process in a manner considered by some to be rushed and superficial (Sullivan et al. 2019). Funders are taking steps to improve representation, seen in examples such as the WFF's support of the Water and Tribes Initiative, which aims to build the capacity of Tribal Nations to meaningfully participate in decision-making (Snyder 2021). Meeting the WFI's stated goal of raising up leaders who are "representative of, and accountable to, the communities they serve, including disadvantaged communities" will benefit from an explicit focus on inclusion, engagement, and participation. Understanding and addressing critical issues, like power dynamics and the assumptions underpinning existing governance, will help to forge collaborative solutions that are more just, equitable, and legitimate (Taylor et al. 2019; Karambelkar and Gerlak 2020).

As numerous drivers increase pressure on earth's ecosystems, philanthropies are going beyond traditional funding roles to become key actors in conservation governance and politics. Ensuring transparency and representation is an important first step in nurturing a more "virtuous cycle" of capacity building and inclusive collective action at multiple scales, from local conservation projects to international efforts to realise the Sustainable Development Goals. Efforts to understand and increase the accountability of philanthropy to the diverse interests in the basin will help to foster collective action at the basin level during a period of profound pressure and change in the Colorado River. In so doing, the experiences of the basin will offer an important set of lessons to regional and international observers about the opportunities and risks of philanthropy to river conservation.

\section{AUTHOR CONTRIBUTIONS}

DG: conceptualisation, methodology, analysis, writing, supervision, approval. GG: conceptualisation, methodology, analysis, writing, project administration, investigation, visualisation, approval.

\section{ACKNOWLEDGEMENTS}

We would like to extend our sincere gratitude to all study participants for their time and insights.

\section{FINANCIAL DISCLOSURE}

We would like to thank St. Catherine's College and the School of Geography and the Environment for field work support for GG.

\section{CONFLICTS OF INTEREST}

DG received funding from the Walton Family Foundation in 2009 and 2013. DG and GG have collaborated on academic 
and consulting projects with some of the conservation groups receiving funding from the WFI.

\section{Ethics approval}

The study was approved by the Central University Research Ethics Committee (CUREC) of the University of Oxford (reference: SOGE 18A-80).

\section{Data availability}

Interview data is not available due to privacy restrictions. Financial data was collected from public sources as described in the methods section. Please contact the corresponding author with any questions.

\section{NOTES}

1. The Water Funder Initiative was founded in 2016 by the Bechtel Foundation and Walton Family Foundation. Its initial members were the Cynthia and George Mitchell Foundation, Energy Foundation, Pisces Foundation, Water Foundation, William and Flora Hewlett Foundation, and Rockefeller Foundation. As of 2021, its members have changed to the Gates Family Foundation, William and Flora Hewlett Foundation, Laural Foundation, Lyda Hill Philanthropies, Cynthia and George Mitchell Foundation, Gordon and Betty Moore Foundation, Carroll Petrie Foundation, and Pisces Foundation.

\section{REFERENCES}

Bureau of Reclamation. 2020. Review of the Colorado River Interim Guidelines for Lower Basin Shortages and Coordinated Operations for Lake Powell and Lake Mead. Washington DC: US Department of the Interior.

Burow, P. B., K. McConnell, and J. Farrell. 2019. Social Scientific Research on the American West: current debates, novel methods, and new directions. Environmental Research Letters 14(12): 125012.

Central Arizona Project. 2016. Lower Basin Drought Contingency Plan Steering Committee. https://www.cap-az.com/departments/planning/ colorado-river-programs/az-dcp-discussion/Lower-Basin-DroughtContingency-Plan-steering-committee. Accessed on August 30, 2020.

Dempsey, J, T.G. Martin, and U.R. Sumaila. 2020. Subsidizing extinction? Conservation Letters 13(1): e12705.

Farley, K E. 2018. Shifting notions of philanthropy: themes in scholarship and practice. Political Science and Politics 51(1): 48-53.

Fleck, J. 2016. Water is for fighting over: and other myths about water in the west. Washington DC: Island Press.

Fleck, J, and B. Udall. 2021. Managing Colorado River risk. Science 327(6545): 885-885.

Garrick, D.E. 2015. Water allocation in rivers under pressure: water trading, transaction costs and transboundary governance in the Western US and Australia. Cheltenham: Edward Elgar Publishing.

Gerlak, A.K., F. Zamora-Arroyo, and H.P. Kahler. 2013. A delta in repair: restoration, binational cooperation, and the future of the Colorado River Delta. Environment: Science and Policy for Sustainable Development 55(3): 29-40.

Gillon, K., M. Cohen, J. Pitt et al. 2006. Appendix K: Conservation before shortage II proposal for Colorado River Operations. In: Colorado River interim guidelines for lower basin shortages and coordinated operations for Lake Powell and Lake Mead: final environmental impact statement. Boulder City, NV: US Bureau of Reclamation.

Holmes, G. 2012. Biodiversity for billionaires: capitalism, conservation and the role of philanthropy in saving/selling nature. Development and Change 43(1): 185-203.

Karambelkar, S. and A.K. Gerlak. 2020. Collaborative governance and stakeholder participation in the Colorado River Basin: an examination of patterns of inclusion and exclusion. Nat. Resources J. 60: 1-46.

Kendy, E., B. Aylward, L.S. Ziemer, et al. 2018. Water transactions for streamflow restoration, water supply reliability, and rural economic vitality in the Western United States. Journal of the American Water Resources Association 54(2): 487-504.

Koebele, E.A. 2020. Cross-coalition coordination in collaborative environmental governance processes. Policy Studies Journal 48(3): 727-753.

Marston, D. 2021. Writers on the range: who calls the shots on the Colorado River? https://www.vaildaily.com/opinion/writers-on-the-range-whocalls-the-shots-on-the-colorado-river/ Accessed on January 28, 2021.

OECD. 2018. Private philanthropy for development, the development dimension. Paris: OECD Publishing.

Ostrom, E. 2009. A general framework for analyzing sustainability of socialecological systems. Science 325(5939): 419-422.

Pitt, J. and E. Kendy. 2017. Shaping the 2014 Colorado River Delta pulse flow: rapid environmental flow design for ecological outcomes and scientific learning. Ecological Engineering 106: 704-714.

Poteete, A.R. and E. Ostrom. 2004. In pursuit of comparable concepts and data about collective action. Agricultural Systems 82(3): 215-232.

Reisner, M. 1993. Cadillac desert: the American West and its disappearing water. New York, NY: Penguin.

River Network. 2017. 2017 Colorado River Basin Water Transactions Workshop. https://www.rivernetwork.org/2017-colorado-river-basinwater-transactions-workshop/ Accessed on August 30, 2020.

Snyder, M. 2021. Tribal expertise, engagement is critical to the West's water future. https://www.waltonfamilyfoundation.org/stories/environment/ tribal-expertise-engagement-is-critical-to-the-wests-water-future. Accessed on May 22, 2021.

Sullivan, A., D.D. White, M. Hanemann. 2019. Designing collaborative governance: insights from the drought contingency planning process for the lower Colorado River basin. Environmental Science \& Policy (91):39-49.

Taylor, K.S., S. Longboat, and R.Q. Grafton. 2019. Whose rules? a water justice critique of the OECD's 12 principles on water governance. Water 11(4): 809-828.

Tory, S. 2017. Money for water: a pilot project wins over skeptical farmers and ranchers. https://aspenjournalism.org/money-for-water-a-pilotproject-wins-over-skeptical-farmers-and-ranchers/. Accessed on February 19, 2021

WFI (Water Funder Initiative). 2016. Toward water sustainability: a blueprint for philanthropy. https://static1.squarespace.com/ static/5e98c7fe 7db4f0180a3586b4/t/5eb5e7927d843102f6aff5 aa/1588979605650/Water-Funder-Initiative-Blueprint-March-15-2016. pdf. Accessed on August 30, 2020.

WFI (Water Funder Initiative). 2020. Toward water sustainability: a campaign to support transformative water solutions. https://static1.squarespace. $\mathrm{com} / \mathrm{static} / 5 \mathrm{e} 98 \mathrm{c} 7 \mathrm{fe} 7 \mathrm{db} 4 \mathrm{f} 0180 \mathrm{a} 3586 \mathrm{~b} 4 / \mathrm{t} / 605 \mathrm{~b} 868 \mathrm{~b} 3 \mathrm{~b} 1 \mathrm{fad} 467$ 2e70453/1616610956654/WFI_Campaign_Overview.March2021.pdf. Accessed on February 19, 2021.

Zamora-Arroyo, F., J. Pitt, S. Cornelius, et al. 2005. Conservation priorities in the Colorado river delta, Mexico and the United States. Tucson, AZ: Sonoran Institute, Environmental Defense, University of Arizona, Pronatura Noroeste Dirección de Conservación Sonora, Centro de Investigación en Alimentación y Desarrollo, World Wildlife Fund - Gulf of California Program. 